\title{
A Determinant Of Healthy Ageing - Women Education In Saudi Arabia
}

\author{
Nadia Yusuf, King Abdul-Aziz University, Saudi Arabia \\ Laila Al-sharqi, King Abdulaziz University, Saudi Arabia \\ Farah Durrani, University of Business and Technology, Saudi Arabia
}

\begin{abstract}
An increase in the number of elderly people has major implications for society, affecting such areas as health and social services and public spending. The economic effects of an ageing population are considerable. Older people have more savings than younger people, but spend less on consumer goods. The rise in ageing populations will also increase some categories of expenditure, like health care, whose cost is likely to increase dramatically as the population ages. Saudi Arabians, while relatively enthusiastic about saving in general, see retirement as a less important incentive to save and have reduced retirement savings as a result of the current economic downturn. At the same time, life expectancy will be higher and birth rate will decline because of the increase of education levels. People's concepts of birth and health care will be improved under the function of education. Education is the single most important indicator of the socioeconomic status of an individual, which affects almost all aspects of human life, including demographic health behavior. Change of the increase of population ageing that is caused by the change of the relative number of independent variables, such as education, is more of a concern.
\end{abstract}

Keywords: Ageing; Economic; Education; Expenditure; Population; Women

\section{INTRODUCTION}

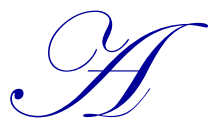

male guardian required by all women, regardless of age, originates from the Islamic law and the culture of the various communities in Saudi society. Women were barred to vote or be elected to high political positions. With the evident changes in Saudi Labor Law, women are presently taking part in the labor force. The sudden oil wealth provided great opportunities for development, but traditional cultural and religious attitudes, as well as the country's educational and employment policies, have been a major constraining factor. The Saudi educational policy is meant to ensure that the Kingdom's education is much more efficient in a manner that it is able to meet the socio-economic needs of learners and the country in general.

A survey conducted in 2006 by the government indicated that well over 80 percent of women in Saudi Arabia are against women driving or working with men (Butters, 2009). This indicates that the women in this Kingdom are still supportive of the cultural gender roles and are especially closely connected to the Islamic values despite already having a higher level of independence (Saleh, 2010). According to the segregation law, there should be physically and visually separate sections for the sexes at all meetings, including weddings and funerals. Institutions where there might be exceptions include medical schools, financial institutions and hospitals. The Sharia (Islamic Law) also may permit women to work only in the event that this does not affect her role in ensuring that the family is taken care of. In addition, women may also be involved in economic activities in cases where they need to provide support on their own, like in the case of widowed women or as long as their husbands or their male guardians permit them. The popular literature about Saudi women focuses primarily on their veiling, gender segregation, and limited options (Sanabary, 1993). It often fails to recognize that they have indeed made major progress in various spheres of life over a relatively short time. It is practically impossible to discuss women's education in Saudi Arabia without introducing the social and political forces that have shaped women's status, not only in education, but in society in general. Women's role in education in Saudi Arabia's conservative society serves as a force to always identify with. Despite the fact that the society and tradition favor men's education over 
women's, the disparity between boys and girls in the distribution of educational funds is a clear and logical reflection of gender hierarchies in the overall society. It is worth being optimistic. Under the patronage of King Abdullah, women's education has boomed in recent years.

\section{OBJECTIVE}

The objective of this paper is to establish the features influencing women in higher education. Encouraged by better education, a changing economy, and more opportunity, Saudi women are entering new, unorthodox business and industrial professions.

\section{Significance}

Education is a key part of strategies to improve individuals' well-being and society's economic and social development. It contributes directly to the growth of national income by improving the productive capacities of the labor force. As a result, this research is helpful in determining the great connection between education and the wellbeing of Saudi women. The information obtained will be helpful for policymakers, women interest groups and all Saudi citizens who are more than ever interested in the issue of gender equity.

\section{RESEARCH METHODOLOGY}

The authors start with the introduction of the world's wealthiest desert kingdom and the rise in higher education within the kingdom and further verify the role of Saudi government in building an educational infrastructure that has led to an increase in school and university enrolment reducing the illiteracy rates. This research work is based on secondary data collected from varied sources, including the higher education ministry. Moreover, interviews and questionnaires are comprised in the primary data. As such, the research adopts a qualitative design.

\section{Education: The Framework}

Since the 1920s, a small number of private institutions have offered limited secular education for boys, but it was not until 1951 that an extensive program of publicly-funded secondary schools was initiated. In 1957, the first university not dedicated to religious subjects - Riyadh University, subsequently renamed King Saud University was established. Publicly-funded education for girls began in 1960 under the inspiration of then Crown Prince Faisal and his wife Iffat. The concern was compounded by the fact that women as a group have excelled academically over males in secondary schools, even though the number of girls entering school was considerably lower than the number of boys.

\section{Government Expenditure On Education}

Government funding for higher education has been particularly magnificent. For instance, between 1983 and 1989, the number of university students increased from approximately 58,000 to about 113,000, which represented a massive 95 percent increase within the six-year period. Equally dramatic was the increase in the number of women students at the university level: from 20,300 to 47,000 during the same period, or a 132 percent increase [Table 1] (UNESCO, 2008). 
Table 1: Public Expenditure On Education In The Arab World (2002-2008)

\begin{tabular}{lcccc}
\hline & \multicolumn{4}{c}{ Public Expenditure On Education } \\
\cline { 2 - 5 } \multicolumn{1}{c}{ Countries } & \multicolumn{3}{c}{ As \% Of GDP } & As \% Of Total Government Expenditure \\
\cline { 2 - 5 } & $\mathbf{2 0 0 2}$ & $\mathbf{2 0 0 8}$ & $\mathbf{2 0 0 2}$ & $\mathbf{2 0 0 8}$ \\
\hline Algeria & - & 4.3 & - & 20.3 \\
Bahrain & - & 2.9 & - & 11.7 \\
Egypt & - & 3.8 & - & 11.9 \\
Kuwait & 6.6 & - & 14.8 & - \\
Lebanon & 2.6 & 2.0 & 12.3 & 8.1 \\
Morocco & 5.8 & 5.7 & 26.4 & 25.7 \\
Oman & 4.3 & - & 22.6 & - \\
Saudi Arabia & $\mathbf{7 . 7}$ & $\mathbf{5 . 7}$ & $\mathbf{2 6 . 9}$ & $\mathbf{1 9 . 3}$ \\
United Arab Emirates & 2.0 & 0.9 & 23.5 & 27.2 \\
\hline
\end{tabular}

Note: Institute for Statistics; for the UAE, the 2002 data are a national estimate.

According to the higher education ministry, the first public girls' school was only built by 1964 and by the end of the 1990's, every region had one of these schools. Progressively by end of 2004, about half of all school enrolments in the Kingdom were composed of women. The Saudi government has been struggling to ensure that the right to education is provided to all male and female citizens, free of charge without any inequity. As a result, the expenditure by government on education in the past years has shown a tremendous mounting graph as shown in Figure 1 (AlMunajjed, 2009).

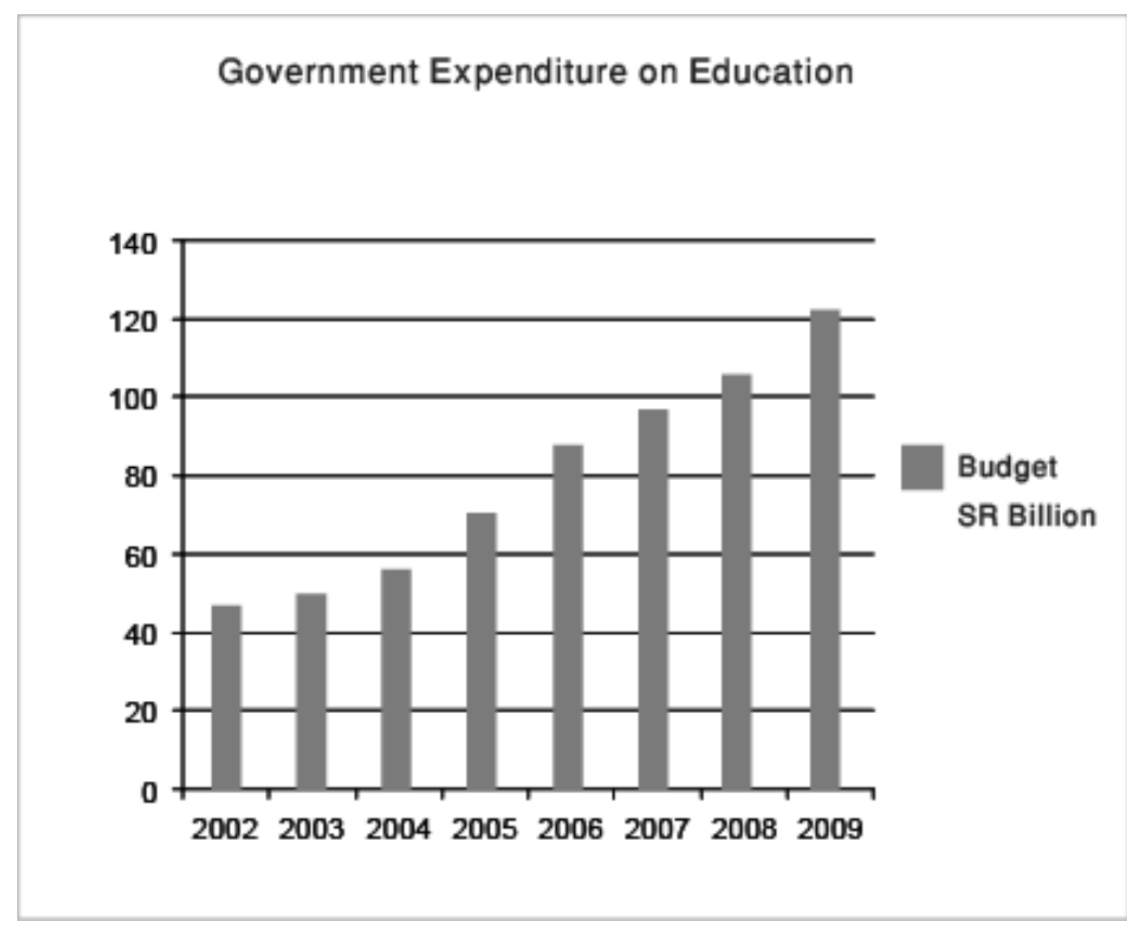

Figure 1: Government Expenditure On Education (2002-2009)

To help bring the increasing number of female students in schools, in 1974-75, there were 1,024 female schools, which represented 26 percent of the total number of schools at all levels. After 30 years, the number of female schools has since increased to 24,464 and represented 49 percent of the total number of schools at all levels. This increase can be attributed to active facilitation by the government to ensure adequate and equitable learning resources and institutions alike. For instance, the government has succeeded in building an educational infrastructure that has led to an increase in school and university enrolment as well as a reduction in illiteracy rates, as shown in Table 2 (UNESCO, 2008). 
Table 2: The Literacy Rate In Saudi Arabia

\begin{tabular}{lcccc}
\hline \multicolumn{1}{c}{ Literacy Rate } & $\mathbf{1 9 9 2}$ & $\mathbf{2 0 0 0}$ & $\mathbf{2 0 0 4}$ & $\mathbf{2 0 0 8}$ \\
\hline Youth Female age 15-24 (\%) & - & 93.7130629 & 94.6757072 & 96.2 \\
Youth Male age 15-24 (\%) & - & 98.0742835 & 96.9530482 & 98.4 \\
Youth Total age 15-24 (\%) & - & 95.9131588 & 95.8496913 & 97.3 \\
Adult Female age 15 and above & 57.2778413 & 69.2911928 & 79.6530768 & 80.2 \\
Adult Male age 15 and above & 79.9685268 & 87.0607739 & 89.4531134 & 89.5 \\
Adult Total age 15 and above & 70.8216499 & 79.3509442 & 85.38729 & 85.5 \\
\hline
\end{tabular}

\section{Government Reforms}

Since the introduction of the First Development Plan in 1970, there has been substantial growth of the Kingdom's educational system and improved quality as well. This can be gauged by the comparison between the growth in number of students in relation to that of full-time teachers. Whereas in the period between the 1970s and the 1990s the number of students grew six times, the number of full-time teachers grew nine-fold. However, the teacher-student ratio in the country - at 1 per 15 students - still remains one of the lowest in the world. The introduction of technology has been helpful in alleviating this situation. The government has also been at the forefront of making sure that quality is enhanced and the introduction of computer science course at the high school level by 2006 is a good example of its efforts.

The government has not restricted its efforts to the younger generation. Literacy courses are also being offered to older women. The government supports these classes financially, administratively and technically. Older women are enrolled in adult education programs. These initiatives have created more jobs for female teachers. On a positive note, the government has become aware of the need to improve the education system and increase women's participation in order to ensure economic survival.

With respect to the main interest of this research, the Saudi government also provides opportunities to young Saudi women at all levels of higher education, with incentives in the form of allowances throughout their years of study. It is, therefore, not surprising to note that women have formed the majority of enrolments in learning institutions in the country today. As a matter of fact, government statistics indicate that the total number of female students seeking a bachelor's degree has tripled from 93,486 in 1995-96 to 340,857 in 2005-06 (AlMunajjed, 2009). The number of vocational institutes for women reached 27 in 2004-05, with more than 3,408 women students studying home economics (Altorki, 1986). A number of private schools and universities for girls have opened under the supervision of the country's education ministry. The special emphasis given by the Saudi government in achieving its objectives has led to an increase in the allocation for education, as shown in Table 3.

Table 3: Government Appropriations For Education (In Millions SR) 2004-2009

\begin{tabular}{lccccc}
\hline Agencies & $\mathbf{2 0 0 4 - 2 0 0 5}$ & $\mathbf{2 0 0 5 - 2 0 0 6}$ & $\mathbf{2 0 0 6 - 2 0 0 7}$ & $\mathbf{2 0 0 7 - 2 0 0 8}$ & $\mathbf{2 0 0 8 - 2 0 0 9}$ \\
\hline Ministry of Higher Education & 466.2 & 911.6 & 3268.7 & 2932.7 & 4229 \\
Ministry of Education (Male) & 25853.4 & 30534 & 31419.5 & 32904.7 & 37221 \\
Ministry of Education (Female) & 26167.1 & 31686.4 & 32069.8 & 33729.5 & 38637 \\
King Saud University (Riyadh) & 2349.6 & 2691.8 & 2718.7 & 3137.6 & 3774 \\
King Fahd University for Petroleum \& Minerals & 561.6 & 646 & 624.9 & 642 & 704 \\
King Abdulaziz Univeristy, Jeddah & 1369.5 & 1604.3 & 1565.2 & 2035.3 & 2345 \\
King Faisal Univeristy & 693.8 & 795.2 & 805 & 1475.9 & 1636 \\
Umm Al-Qura University & 588.9 & 711.9 & 672.5 & 998.5 & 1185 \\
Taibah University & 187.6 & 246.7 & 284.1 & 582.9 & 737 \\
Qaseem University & 296.6 & 390.8 & 413.2 & 748.7 & 888 \\
Taif University & 128.1 & 189.9 & 213.5 & 474.9 & 609 \\
Tabuk University & - & - & 66.7 & 244.4 & 287 \\
Najran University & - & - & 68.1 & 211.6 & 246 \\
Higher Education Council & - & 8.6 & 15.3 & 18.5 & 20 \\
Total & 60462.7 & 72669.6 & 80589.7 & 85348.6 & 98586 \\
Education Projects & 5335.8 & 8685 & 11653.2 & 14799.6 & 18296 \\
Grand Total & $\mathbf{6 5 7 9 8 . 5}$ & $\mathbf{8 1 3 5 4 . 6}$ & $\mathbf{9 2 2 4 2 . 9}$ & $\mathbf{1 0 0 1 4 8 . 2}$ & $\mathbf{1 1 6 8 8 2 . 0}$ \\
\hline
\end{tabular}




\section{Education: The Demand Function}

The changing economy in Saudi Arabia has also made it easier for women to enter the workplace. The Saudi Arabian economy has greatly suffered from the sharp drop in oil prices, which fell from a high of US\$37 per barrel in 1980 to US\$10 per barrel this year. As a result, the nation's per capita GDP has fallen from US\$18,500 in 1981 to US\$6,200 today and has driven women to work to supplement family incomes (Sanabary, 1994).

The Higher Education Council is the Kingdom's overall body authorized to look into matters concerning education in post-secondary institutions. Among others, it is charged with supervising and coordinating all institutions, with the exception of military-based education institutions (Ministry of Higher Education, 2012). In addition, the Council is also charged with regulation of university curriculum according to policy guidelines, supervising the establishment and growth of such institutions within all sectors of the economy; coordination of all university education activities and programs, including scientific faculties and degrees; and promotion of research. It also deals with formulation of the rules and regulations to ensure that all university institutions comply with appropriate policies. In particular, the country's higher education sector has, in recent years, undergone a lot of transforming within the government's quest to eradicate illiteracy and expand on skills among the Saudis. The expanded infrastructural facilities in the Kingdom include:

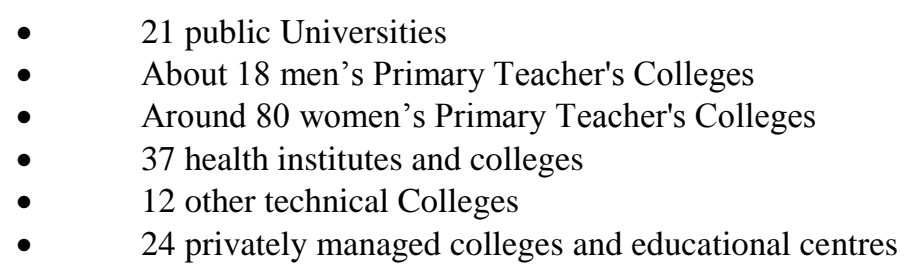

All the mentioned educational institutions offer graduate study programs. The universities have a capacity to offer courses leading to the award of master's and doctoral degrees with options of grants in some fields. Because of the combined effects of the changing economy and increased education of women changing mentalities, it can be estimated that women in the labor force is on a rise. Many professions that previously barred women have started to accept them. Careers in retailing, marketing, and industry are all possibilities for the modern Saudi woman. Women's banking is also a promising field. With its new employment strategy, the government is taking measures to reduce the structural imbalances in the country, including gender disparities.

\section{Limited Fields of Specialization}

Statistics released by the Saudi Ministry of Planning and Human Resources (2003) indicate that the number of single women is increasing dramatically. The primary reason for this trend is the enhancement in women's education. Just as in the West, Saudi women are graduating from universities at higher rates than men and they are taking jobs in education, medicine, and banking. Lately, the country's labor minister has been pushing for legal changes that would allow more women to work in retail jobs and factories. At the university level, education and training for women are limited, as the specializations do not match the needs of the labor market. Women's degrees are concentrated in education and teaching, human sciences, natural sciences, and Islamic studies. College plans to develop broader specializations in other areas of study, such as e-business and health care, is shown in Figure 2. 


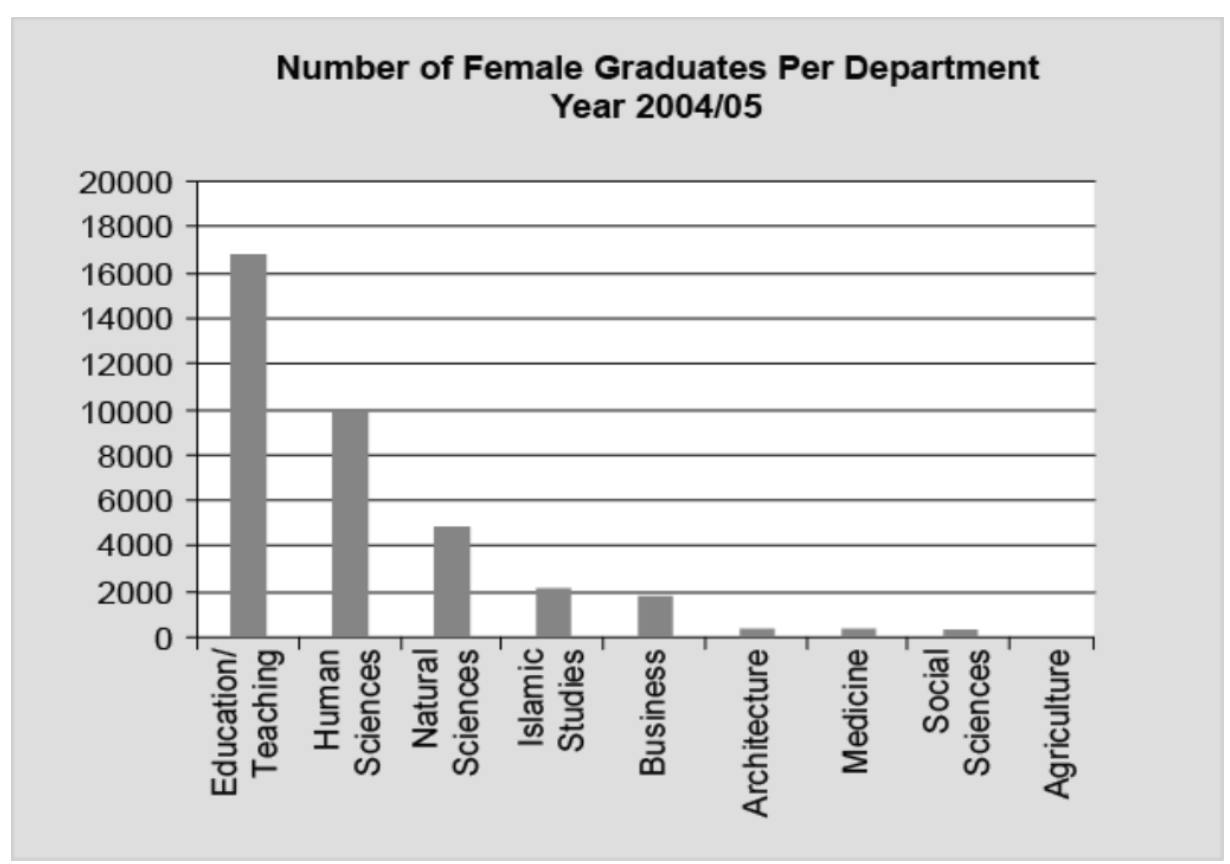

Figure 2: Female Graduate Degrees By Departments (2004-2005) Mehran, 2003

About 80 young Saudi girls have enrolled in the new graduate nursing program developed at the Faisal Specialist Hospital \& Research Centre, according to Dr. Thelma, head of Diploma Program at KFSH \& RC (AlMunajjed, 1997). However, more young Saudi women are approaching the nursing program, something that is leading to a new phenomenon. To be able to withstand international competitiveness, the Saudi population has realized the important role of women in their economy.

\section{With Achievements Come The Challenges}

It may be worth noting here that the place of women in the Saudi culture has been quite a controversial one. Leaving aside the heated debate among Muslim circles on the place of women religiously and socially, women in the kingdom still have to face gender issues. As a result, gains made by women in the educational front have been met with a lot of challenges. The war between a progressive society, on one side, and a conservative one, on the other side, has been on the distinct rights of women in society. Prior to 2002, women's educational institutions were under the department of religious guidelines, as opposed to that of their male counterparts which were under the ministry of education (Ahmad, Brodsky, Crofts, \& Ellis, 2004). This indicates how restrictive society has been with regard to the education of women.

With many developments made to eradicate discrimination, there is still a lot that needs to be done to ensure that the success of women's education is not only measured by the number of enrolments, but on the appropriate learning opportunities and environments offered to them. As a matter of fact, opportunity and conducive environments are two areas of great hindrance to the learning of women in the kingdom despite the fact that it may have come a long way in the advancement of the empowerment of the girl child. The fact that problems in the education sector are often institutionalized, and hence not easy to eliminate, is a disturbing reality to many. Two identified indicators to the challenges women have faced include increased number of women enrolled in studies outside the kingdom and the evident disparity that exists in the funding of education of men and women currently studying abroad. 


\section{Women Study Abroad}

There are many push factors that have led to women in the Kingdom resorting to studying abroad. As mentioned above, the economic standards of women in the oil rich nation have been raised in recent years. As a result, the fact that they are not able to acquire the standard of education they might have dreamt of may push many economically empowered women to look at other options. Even though conservative educators may like to point at the growing influence of western culture in the Kingdom and in other nations, there are factors that have pushed women to resort to learning in foreign schools, which include the dress code, teaching content, admission requirements and relative learning environments.

First, the issue of a veiled dress code, even for school-going women, has been a controversial one in the Kingdom just as it has been in many other states around the globe. It is commendable that the idea behind veiling is to be able to reduce indecent exposure and maintain self-discipline in educational institutions (Helena, 2011). However, as advancements in the rights and choices are going to be made elsewhere, it is no longer left for the institutions to decide on what women should wear, taking into consideration that males do not necessarily have restrictive dressing as their female counterparts. As a result, the strict requirement that women should always be veiled has been a hindrance to the learning of progressive women in the Saudi society. The fact that changing this situation requires a lot of effort, given its religious attachment, may explain why many women have decided to seek other opportunities outside the Kingdom.

Secondly, the content aligned to religious virtues, especially stressed on the women's curriculum, have not been accommodative to the principles of education that require an open mind. It is evident that the education of women in the country has been traditionally embedded on the religious foundations. As such, changing the education systems to align to modern issues facing women in relation to their empowerment has been difficult. As such, it is difficult for the progressive group of women to accept this type of education that they consider restrictive and outdated as part of their curriculum development. Seeking opportunities elsewhere, where learning takes a multicultural and diverse foundation rather than a restricted platform, has therefore become an option for the many Saudi women who have the ability and opportunity to do so.

Apart from curriculum, there are accompanying rigid school rules, especially in institutions handling women's education. First, entry requirements for women are usually tightened and even attached to moral backgrounds. The learning environment is usually full of restrictions for most institutions in the Kingdom that specialize in the development of girl child and women's education (Jamjoom \& Kelly, 2013). Therefore, it is easy to find that girls are restricted on what they eat and wear and who they associate with. The schools compound is usually fenced with high walls and the women are, in most cases, followed by matrons who expect that they observe rules at all times. This restrictive learning environment may not work for most women. As a matter of fact, the quality of learning environment affects the perception of the learners and hence performance. Instead of learning in such a restrictive place, most are finding solace in foreign institutions that recognize the freedom of women and the importance of interaction on learning.

With conditions in most institutions in the country remaining the same, many women will continue to look for opportunities outside the Kingdom (Kono, 2013). Further compounding on this, is the fact that globalization has led to the expansion of boarders making learning in any country relatively easy than it was before. Technology in the education sector will also influence the number of enrolments in schools within the Kingdom, especially those of women. This is because through opportunities, like e-learning, many women will resort to their own private studies rather than joining public institutions. For women not able to travel far looking for education because of economic constraints, there is a good chance that learning through the internet may provide the best alternative. As the current institutions continue to hold onto values and rules that make it difficult for the modern Saudi woman to learn, many will continue to become disillusioned as well. A lack of opportunity to learn abroad will be viewed by many aspiring women as a missed opportunity to get the right education. As educational standards dictate welfare levels, the gains already attained in ensuring that women get the right education may be negated in the future. 


\section{Funding Of Men's Education Internationally}

It is notable that the government has done all it can to ensure that all citizens (regardless of class, gender or race) have an equal opportunity to be educated. The work of government, however, may surpass that of providing basic and elementary education to all citizens. Through scholarships and collaborative exchange programs, the government is able to further enhance the knowledge of the population's scholars by sponsoring their learning abroad. Disciplines like medicine, engineering and architecture, among others, usually benefit from these programs because they are more likely to be given priority by the government. Women in the Kingdom are still enrolled in low numbers in the those areas and, as a result, their chances of getting such funding opportunities from the government are slim, although other disciplines are also relevant for the economic welfare of any society. Social science, for instance, helps us understand the structures, elements and different behaviors existing in societies that may help policymakers understand the Kingdom better. Women who are mostly enrolled in the art courses are therefore left out on unfair grounds. However, this is not the main focus of this section. Of notable effect is the number of men that the government has continued to fund to enable them to attain their credentials elsewhere in the world (PSU, 2013).

The only way the government may help to increase the number of women scholars who, in turn, will help in the recommendation of the best ways of changing the current system without giving up on the values of the society, is to ensure that women also get an equal opportunity to further their career. The funding of external education mostly for women is therefore against the development of women who would have otherwise benefited from such opportunities (Doumato, 2010). Even though the government may have done enough to ensure that women have equal access to education, it should have gone a step ahead to affirm its position by providing scholarship opportunities to women, the same as those of men. Exposure also defines the level of expertise people get from certain schooling systems. Given that funding men to international institutions provides them more exposure than the women, the kingdom's women still remain neglected.

Moreover, there have been concerns that even though many Saudi women continue to be more educated, there are drawbacks in the economic system that have reduced employment opportunities for the educated women (Nasr, 2013). It is indicated that women still have difficulty in getting jobs due to male domination in the Kingdom. Even though the government has made a lot of strides to ensure that more women are educated, it is very worrying to think that all these efforts are meaningless.

\section{Opportunities Unveil}

With the springing up of more and more hospitals and health centers across the Kingdom, there has also been a huge demand for nursing staff, a field that is overwhelmingly dominated by foreigners. According to official statistics, Saudis constitute less than one percent of the nursing profession in the Kingdom. This means that almost all of the wealth flows out of the kingdom, without financial benefits to the locals. The nursing profession may be a good starting ground for Saudi women if given the chance to venture in it. However, they will also need to take personal initiative in order to succeed.

Saudi women face some minor problems along the options of opportunities available to them. The first reason is misunderstanding of what the job entails. Women will need to be sensitized to the role of nurses in the medical profession, which will be important for creating appreciation for this noble profession. The second reason is the social stigma and lack of familial support that Saudi women get when they decide to enter the field. Both reasons make quitting the job a fast decision (see Table 4) (Saudi Arabian Monetary Agency [SAMA], 2010). The fact that women are still sneered at makes the nursing profession a difficult one. As a result, the change of attitude towards nursing should be facilitated not only to women, but also to society at large. Apart from nursing, the same should be done for other professions so that women are not left behind. 
Table 4: Opportunities Unveiled For Saudi Women

\begin{tabular}{ccccccccc}
\hline \multirow{2}{*}{ Year } & \multicolumn{2}{c}{ Ministry Of Health } & \multicolumn{2}{c}{ Other Government Agencies } & \multicolumn{2}{c}{ Private Sector } & \multicolumn{2}{c}{ Total } \\
\cline { 2 - 8 } & Physicians & Nursing & Physician & Nursing & Physicians & Nursing & Physician & Nursing \\
\hline 2000 & 14,950 & 36,495 & 7,588 & 17,664 & 9,445 & 13,262 & 31,983 & 67,421 \\
2001 & 16,111 & 37,666 & 7,439 & 17,349 & 8,906 & 13,326 & 32,456 & 68,341 \\
2002 & 16,645 & 37,918 & 8,406 & 19,487 & 10,717 & 13,913 & 35,768 & 71,318 \\
2003 & 17,623 & 38,019 & 9,331 & 20,142 & 11,542 & 15,953 & 38,496 & 74,114 \\
2004 & 18,621 & 41,356 & 8,856 & 19,421 & 12,788 & 17,810 & 40,265 & 78,587 \\
2005 & 20,219 & 42,628 & 9,343 & 19,913 & 13,786 & 17,453 & 43,348 & 79,994 \\
2006 & 21,265 & 44,395 & 10,233 & 20,488 & 14,091 & 18,985 & 45,589 & 83,868 \\
2007 & 22,643 & 51,188 & 10,808 & 21,462 & 14,468 & 21,085 & 47,919 & 93,735 \\
2008 & 24,802 & 55,429 & 11,592 & 23,536 & 16,444 & 22,333 & 52,838 & 101,298 \\
\hline
\end{tabular}

In most Arab and Islamic countries, a stereotype of the nurse as a subservient uneducated female hospital worker discourages many Arab women from entering into nursing. The jobs of physician and nurse are marked on the scale of prestige. The opposing images of the two professions prompt women to gravitate toward medicine and shy away from nursing, as shown in Figure 3 (Farag, 2008).

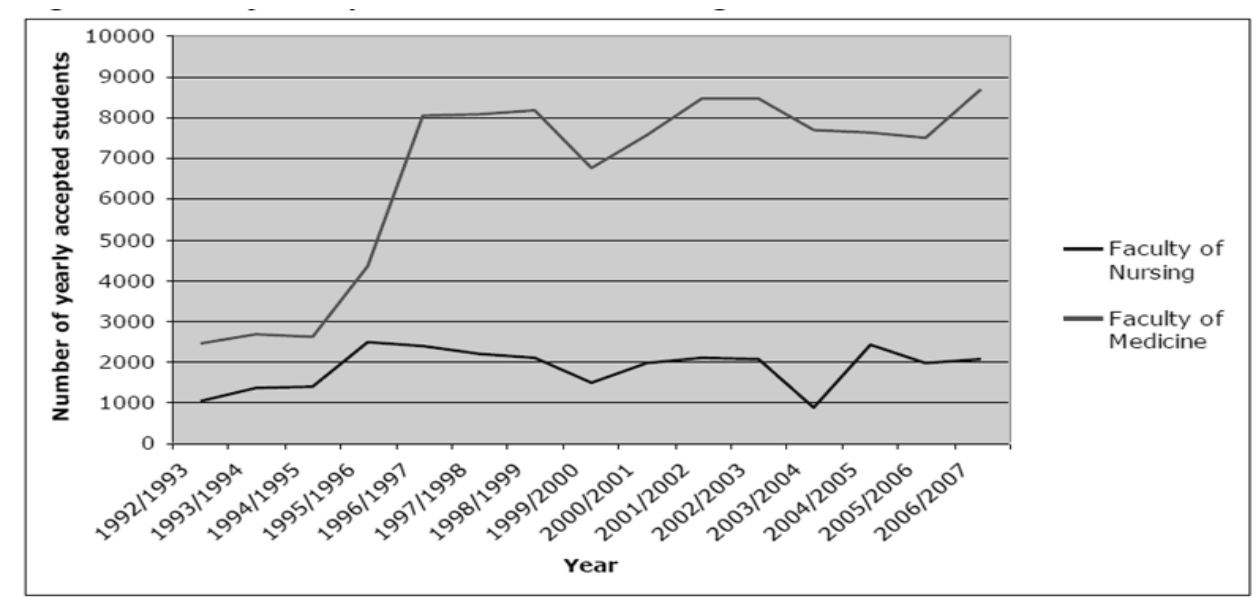

Data Source: High Council for University Education

Figure 3: Difference In Professional Decision Amongst Women

\section{Human Resource Development}

Women's education is associated with vital measures of human resource development, such as reducing population growth and mortality rates, improving health and nutrition, and increasing literacy rates. The Central Department of Statistics and Information reveals key indicators of the change in economic development, as shown in Table 5 .

Table 5: The Key Indicators In The Development

Saudi's Unemployment rate 2012

Revised Economic Participation rate 2012

$12.10 \%$

$39.60 \%$

Infants mortality rate (per thousand live births) 2012

$16.2 \%$

Gross enrollment rate (primary education 2011)

$106 \%$

\section{SUGGESTION \& CONCLUSION}

Education is a key part of strategies to improve individuals' well-being and societies' economic and social development. It contributes directly to the growth of national income by improving the productive capacities of the labour force. Education is one of the most important factors of human capital development, whereas human capital has been identified as a key determinant of growth and poverty alleviation. Saudi Arabia's policies and programs are promising steps toward full participation of women in the labor market. Thus, the study shows that the demand of 
higher education of women stands out as a significant factor in determining fertility rate, sustenance rate for women, illiteracy rate for women, unemployment rate for women, and female participation in the labor force. It mostly operates through some intervening educational attainments that argue in favor of keeping education variables in the empirical specification. With more girls graduating every year with specific career goals, the country witnesses the major demographic change in birth control and rise in economic growth. Eventually, in addition with better health care, higher life expectancy and lower immigration, the Kingdom is on the verge of entering a challenging front of an 'ageing population'.

Research shows that economic problems may influence a social shift in issues around women's education. Ironically, a study by Abu-Baker on male university students conducted in 1980 showed that 70 percent of men would not prefer to marry an educated college graduate, nor did they want their wives to participate in the house budget since they considered that a threat to their authority.

King Abdullah bin Abdul Aziz Al Saud laid the foundation stone for the new infrastructure of Princess Noura bint Abdul Rahman University for women in October 2008. The university is designed to become one of the largest centers of higher education for Saudi women, presenting them with new educational opportunities to enter the labor market. It is clear that the Saudi government is serious about improving the quality of girls' education and has started to implement a new reform policy. These reforms are still at an initial and exploratory stage and it may take a few years before their impact is evident. If the country plans to survive this globalized era, women's education in all fields should be a priority. Educated open-minded individuals' demands would bring about changes and progress.

\section{AUTHOR INFORMATION}

Dr. Nadia Yusuf has a doctorate in Economics and her major is in Microeconomics. Her thesis was based on the role of lead bank in financing the agricultural sector in India, with reference to Aligarh District. She is presently working as an Assistant Professor in the Economics Department at King Abdul-Aziz University, Jeddah, K.S.A. With more than nine years of experience, teaching has become her passion. She teaches students using a systematic plan of lectures, demonstrations, discussion groups, laboratory work, shop sessions, seminars, case studies, field assignments and independent or group projects. Email: nadiayusuf112@ hotmail.com.

Dr. Laila Al-sharqi is an assistant professor of English in the Department of European Languages and Literature at King Abdulaziz University, Saudi Arabia. Her teaching experience covers areas of Literary Theory, Fiction, Modern and Postmodern Literature, and ESL. She was awarded a PhD in Cultural Studies at the University of Nottingham in 2006. She held administrative positions at (KAU) as Deputy Director of the English Language Center (2006-2009) and Vice Dean for Alumna Affairs (2009-2012). She also worked as the Deputy Director of the Center for Talent and Creativity (2010-2012) and was recently appointed as Deputy Director of the Center for Strategic Studies (2012).

Ms. Farah Durrani possesses eight years of experience in teaching a vibrant mix of courses like Introduction to Business Studies, Financial Accounting, Financial Management, Macroeconomics, Organizational Behavior, Marketing Strategy, Business Finance, International Finance, Corporate Finance, International Monetary Economics, Money and Banking, Banking Management, and Islamic Banking and Finance. She also headed the teams working on curriculum development, accreditation facilitation and strategic planning of educational institutes.

\section{REFERENCES}

Ahmad, I., Brodsky, H., Crofts, M. S., \& Ellis, E. G. (2004). World cultures: a global mosaic. Teacher's Ed. Upper Saddle River, NJ: Prentice Hall.

AlMunajjed, M. (1997). Women in Saudi Arabia Today. United States: St. Martins Press.

Altorki, S. (1986). Women in Saudi Arabia: Ideology and behaviour among the elite. New York: Columbia University Press.

Butters, L. A. (2009). Saudi's small step. Time Magazine. Retrieved, 19 October 2009.

Central Department of Statistics and Information. (2013). Kingdom of Saudi Arabia, accessed on March 9, 2013. 
Doumato, E. (2010). 'Saudi Arabia', in Sanja Kelly and Julia Breslin, eds., (2010) Women's Rights in the Middle East and North Africa. New York, NY: Freedom House.

Farag, M. (2008). Economic analysis of the nurse shortage in Egypt. Dubai School of Government, June 2008.

Helena, A. (2011). Teaching Leadership to Female Students in Saudi Arabia. Advancing Women in Leadership, Vol. 31 Issue 1, p199-212.

Jamjoom, F., \& Kelly, P. (2013). Higher Education for Women in the Kingdom of Saudi Arabia. Higher Education Dynamics, Vol 40, (1): pp. 117-125.

Kono, Y. (2013). Globally mobile Saudi students. Retrieved Dec 16, 2013 from http://wenr.wes.org/2013/07/globally-mobile-saudi-students-agents-of-economic-social-culturaltransformation/.

Mehran, G. (2003). The Paradox of tradition and modernity in female education in the Islamic republic of Iran. Comparative Education Review, 47 (3), 269-286.

Ministry of Higher Education. (2012). Kingdom of Saudi Arabia, accessed on March 1, 2013.

Mosa, A. A. (2000). Pressure in Saudi Arabia, International Higher Education.

Nasr, D. (2013). Saudi women more educated than men are wasted resource. Retrieved Dec 16, 2013 from http://www.bloomberg.com/news/2013-06-04/saudi-women-more-educated-than-men-are-wastedresource.html.

PSU. (2013). Saudi Arabia - Higher Education. Retrieved Dec 16, 2013 from http://global.psu.edu/info/academicsresearch/global-engagement-network/regional-resources/regional-resources-saudi-arab-1.

Saleh, A. F. (2010). Saudi women rise in defense of the veil. Washington Post, Retrieved 23 June 2010.

Sanabary, E. N. (1993). The education and contribution of women health care professionals in Saudi Arabia. Social Science and Medicine, vol. 37, no. 11, pp. 1331-1343.

Sanabary, E. N. (1994). Female and education in Saudi Arabia and the reproduction of gender division. Gender and Education. 2, 145.

Saudi Arabian Monetary Agency (SAMA). (2010). The $46^{\text {th }}$ Annual Report “The Latest economic developments", Research and Statistics Department.

Saudi Ministry of Planning and Human Resources. (2003). Riyadh. Saudi Arabia.

UNESCO. (2008). Education for All. Global Monitoring Report, 2008. 


\section{NOTES}

